\title{
A simple approach with scale-up potential towards intrinsically flame-retardant bio- based co-plasticizer for PVC artificial materials
}

\author{
Yong $\mathrm{Xu}^{1}$, Songhang Wang ${ }^{2}$, Jinming Chang ${ }^{3,4}$, Zhou X ${ }^{5}$, Qi Zeng ${ }^{2}$, Zhonghui Wang ${ }^{2}$, Jun Yan ${ }^{2^{*}}$ and Yi Chen ${ }^{1,2}$
}

\begin{abstract}
As an imitation of genuine leather, polyvinyl chloride (PVC) artificial materials are versatile, but suffers from being flammable due to the presence of large amounts of combustible plasticizers. Under such circumstance, intrinsically flame-retardant plasticizers displaying dual functions have been a subject of intensive research interest. However, previous strategies attempting to covalently attach flame-retardant moiety to plasticizers invariably required either expensive starting materials or laborious and tedious procedures, ultimately limiting their scale-up application in industry. In addition, driven by escalating demand of halogen-free flame retardants worldwide from an environmental health perspective, previously reported intrinsically flame-retardant plasticizers were mainly halogenfree, less attractive in PVC artificial material industry simply because PVC itself is a halogen-containing polymer. Here, we report an approach to introduce chlorine moieties into unsaturated fatty acid methyl ester by a simple addition reaction occurring on carbon-carbon double bonds, yielding a chlorine-containing, intrinsically flameretardant bio-plasticizer. When combined with di-(2-ethylhexyl) phthalate (DOP) in PVC formulations, the chlorinated fatty acid methyl ester is qualified as a co-plasticizer while conferring flame retardancy upon the PVC coatings. This approach involves only a one-step procedure that employs renewable fatty acid methyl esters and cheap chlorine gas as raw materials, thus being of great potential to enable intrinsically flame-retardant bioplasticizers on a large scale to manufacture functional PVC artificial materials for application in fire-prone scenarios.
\end{abstract}

Keywords: Plasticizer, Fatty acid methyl ester, Chlorine, Polyvinyl chloride, Artificial material

\section{Introduction}

Polyvinyl chloride (PVC) artificial materials consist of a fabric laminated with one or several PVC coatings to make them look and feel like genuine leather. Ever since their commercial debut in 1930s, PVC artificial materials, by virtue of their low-cost and excellent mechanical properties, have achieved a high share of markets as an imitation of genuine leather. PVC resin itself is nonflammable in terms of the synergism of the following mechanisms

\footnotetext{
* Correspondence: yanjunxy@scu.edu.cn

${ }^{2}$ Key Laboratory of Leather Chemistry and Engineering of Ministry of

Education, Sichuan University, Chengdu 610065, P.R. China

Full list of author information is available at the end of the article
}

[1-3]. Once introduced into a flame, PVC emits chlorine that reacts with oxygen, decreasing the concentration of oxygen that is necessary for burning. Also, burning PVC swells to form a condensed layer, which obstructs the free flow of oxygen. However, commonly used PVC plasticizers, including ortho-phthalates, epoxidized fatty acid methyl esters, and epoxidized triglycerides, etc., are invariably vulnerable to flame $[4,5]$, making the plasticized PVC coatings easily flammable, ultimately limiting their application in fire-prone scenario.

Currently, two strategies are available for improving the flame retardancy of PVC artificial materials. One is to use inorganic flame retardants, such as aluminum 
hydroxide, cerium oxide, antimony trioxide or zinc borate. Efficient as this approach is, inorganic flame retardants are incompatible with PVC resin, thus deteriorating mechanical properties of the PVC coatings $[6,7]$. The other method centers around the application of plasticizers that bear covalently attached flameretardant moieties, namely intrinsically flame-retardant plasticizers. Driven by escalating demand of halogen-free flame retardants worldwide from an environmental health perspective, previously reported intrinsically flame-retardant plasticizers were mainly halogen-free. One compelling example [8] of halogen-free intrinsically flame-retardant plasticizers is reported by Puyou Jia et al who employed methyl ricinoleate as feedstocks to react with 1,3,5-tris (2-hydroxyethyl) cyanuric acid by alcoholysis. The resulting intermediate then reacted with diethyl chlorophosphate, yielding a bio-plasticizer with synergistic flame retardant groups of nitrogen and phosphorus. Another example [9] highlighting how intrinsically flame-retardant plasticizers containing no halogen can be obtained is a recently published study by Wang Fang et al. They designed and prepared a phosphoruscontaining intermediate by allowing neopentyl glycol to react with phosphorus oxychloride. Subsequently, the intermediate was covalently conjugated onto methyl ricinoleate by the reaction between phosphoryl chloride and the midchain hydroxyl group in methyl ricinoleate, yielding a phosphorus-containing flame retardant bio-plasticizer. Despite the flame retardancy those previous plasticizers could confer on PVC artificial materials, their synthesis required expensive starting materials, as well as laborious and tedious procedures, ultimately limiting their scale-up application in industry. In addition, halogen-free flame retardants usually exhibit better toxicological profiles than those contain halogen moieties. However, halogen-free intrinsically flame-retardant plasticizers are less attractive in PVC artificial material industry, simply because PVC itself is a halogen-containing polymer. Thus, developing an approach towards intrinsically flame-retardant plasticizers using cheap raw materials and simple, scale-up synthesis procedure, rather than overemphasizing they are halogen free or not, is desirable, especially in PVC artificial material industry where cost-efficiency is particularly highlighted.

Here, we report a simple strategy to introduce chlorine moieties into unsaturated fatty acid methyl ester by addition reactions occurring on carbon-carbon double bonds, yielding a chlorine-containing, intrinsically flameretardant bio-plasticizer. When combined with DOP in PVC formulations, the chlorinated fatty acid methyl ester is qualified as a co-plasticizer, while endowing the PVC coatings with flame retardancy. This approach employs renewable fatty acid methyl esters, as well as cheap chlorine gas as raw materials, and involves only a onestep procedure, thus being of great potential to enable intrinsically flame-retardant bio-plasticizers on a large scale, particularly suitable for developing functional PVC artificial materials applied in fire-prone scenarios.

\section{Experimental}

\subsection{Materials}

Unsaturated fatty acid methyl ester (FAME, iodine value $=62 \mathrm{gI}_{2} / 100 \mathrm{~g}$ ) and epoxidized fatty acid methyl esters $($ EFAME, epoxy value $=$ ca. $5.8 \%$ ) were supplied by Jingu Plasticizer Co., Ltd. (Shijiazhuang, China). Chlorine gas $\left(\mathrm{Cl}_{2}, 99.8 \%\right)$ was purchased from Keyuan Gas Co., Ltd. (Chengdu, China). Herein, the PVC resin adopted was an SG-5 suspension-grade powder with a K-value of 68-66, provided by Jinlu Resin Co., Ltd. (Chengdu, China). The thermal stabilizer was composed of a 5096 Calcium/Zinc system (Goldstab Organics Pvt. Ltd., India) and a Rhodiastab ${ }^{\circ} \beta$-diketone compound (Solvay Chemicals, China) in a weight ratio of 10:1. Di(2-ethylhexyl) phthalate (DOP, 99\%) and cyclohexane (99\%) were purchased from Chron Chemicals Co., Ltd. (Chengdu, China). All reagents were used without further purification unless otherwise stated.

\subsection{Synthesis of chlorinated fatty acid methyl ester (CFAME)}

Chlorinated fatty acid methyl ester (CFAME) was synthesized by addition reaction between unsaturated FAME and chlorine gas. Briefly, dehydrated FAME ( $80 \mathrm{~g}$ ) were introduced into a $250 \mathrm{~mL}$ three-necked flask, which was equipped with a thermometer, a magnetic stirrer and an absorbent for exhaust gas. Then chlorine gas was introduced at a certain flow rate to ensure sufficient contact with the feedstock. The reaction was carried out at a fixed temperature for a period of time. At a fixed time interval, a small amount of the feedstock was withdrawn with its chlorinity being measured. After the reaction, the mixture was cooled to ambient temperature, and extensively bubbled by dried air for $48 \mathrm{~h}$. To stabilize the resulting CFAME, commercial epoxidized fatty acid methyl esters (EFAME, $4 \mathrm{~g}$ ) with an epoxy value of ca. $5.8 \%$ was added into the product, which was then stored in a sealed bottle protected from light. The synthesis procedure and chemical structure of CFAME were illustrated in Scheme 1.

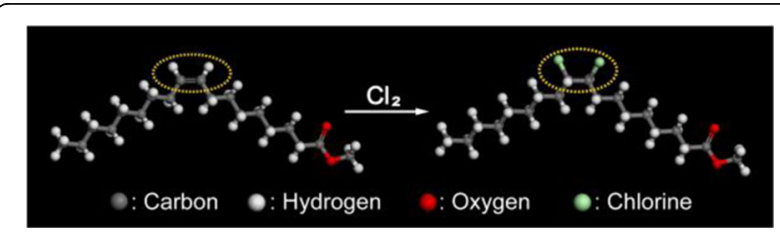

Scheme 1 Preparation procedure of chlorinated fatty acid methyl ester (CFAME) 


\subsection{Preparation of plasticized PVC coating}

To obtain flexible PVC coatings, a two-pot blending approach previously disclosed by B.I. Chaudhary et al. [10] was employed. Briefly, PVC powder and thermal stabilizer (2 phr) were first mixed in a container, followed by stirring at $90^{\circ} \mathrm{C}$ and $40 \mathrm{rpm}$ for $2 \mathrm{~min}$. The plasticizer mixture (50 phr in total) composed of DOP and CFAME, preheated at $90^{\circ} \mathrm{C}$, was then added into the mixture, and stirred at $90^{\circ} \mathrm{C}$ and $40 \mathrm{rpm}$ until complete plasticizer absorption. Subsequently, the blend was heated to $150^{\circ} \mathrm{C}$, and melt-mixed at $40 \mathrm{rpm}$ using HTK-200 cam rotors for $5 \mathrm{~min}$, followed by being pressed using a $\mathrm{CH}-0201$ two-roll mill at $12 \mathrm{rpm}$ and $150{ }^{\circ} \mathrm{C}$ for $15 \mathrm{~min}$. This afforded a transparent and flexible PVC coating with an average thickness of $0.2 \mathrm{~mm}$, conditioned in a desiccator containing silica gel for $48 \mathrm{~h}$ prior to characterization. The PVC coatings were referred to as PVC/CFAME $x$, wherein $x$ indicated the percentage of CFAME in the plasticizer mixture. Detailed composition of the as-prepared PVC coatings was tabulated in Table 1.

\subsection{Characterization}

The chlorinity and iodine value of the as-synthesized plasticizers were determined according to Chinese Chemical Industry Standard HG 3017-1988 [11] and Chinese Standard GB/T 1676-2008 [12], respectively. Fourier transform infrared (FT-IR) spectra were collected on a Nicolet iS10 FT-IR spectrometer (Thermo Scientific, U.S.) at a resolution of $2 \mathrm{~cm}^{-1}$ after 32 scans. Gas chromatography-mass spectrometry (GC-MS) (Agilent Techn., Inc., 7890A/5975C, Rxi-5MS column) was employed to analyze the composition of CFAME. The initial column temperature was held at $100{ }^{\circ} \mathrm{C}$, and then to $240{ }^{\circ} \mathrm{C}$ at $3{ }^{\circ} \mathrm{C} / \mathrm{min}$. Helium $(99.99 \%)$ was used as carrier gas at a flow rate of $10 \mathrm{~mL} / \mathrm{min}$. MS data was obtained with an ion source temperature of $230^{\circ} \mathrm{C}$. The components were identified by comparing the experimental mass spectra with those references available in NIST08.LIB. Plasticizing efficiency was measured by using a DMA242C dynamic mechanical analyzer (Netzsch, Germany) in the tensile mode at a fixed frequency of $0.5 \mathrm{~Hz}$ under $\mathrm{N}_{2}$. To determine migration resistance of CFAME, the PVC coatings $(50 \mathrm{~mm} \times 50 \mathrm{~mm}$ )

Table 1 Composition of PVC/CFAMEX

\begin{tabular}{llll}
\hline & DOP (phr) & CFAME (phr) & Stabilizer (phr) \\
\hline PVC/CFAME0 & 50 & 0 & 2 \\
PVC/CFAME20 & 40 & 10 & 2 \\
PVC/CFAME40 & 30 & 20 & 2 \\
PVC/CFAME60 & 20 & 30 & 2 \\
PVC/CFAME80 & 10 & 40 & 2 \\
PVC/CFAME100 & 0 & 50 & 2 \\
\hline
\end{tabular}

were sandwiched between two pieces of filter paper. The assembly was pressed by a flat bottom block $(1 \mathrm{~kg})$, and placed in an air circulating oven at $70^{\circ} \mathrm{C}$ for $48 \mathrm{~h}$ before re-weighing and calculating their percentage reduction in weight, as described by International Organization for Standardization (ISO) test method 177:2016(E) [13] ${ }^{\cdot}$ To determine resistance of the plasticizers to extraction, the PVC membranes $(50 \mathrm{~mm} \times 50 \mathrm{~mm} \times 0.2 \mathrm{~mm})$ were soaked in cyclohexane, and thermostated at $30^{\circ} \mathrm{C}$ for 48 h. Subsequently, the PVC membranes were dried at $30^{\circ} \mathrm{C}$ for $24 \mathrm{~h}$, and then placed in a desiccator at room temperature for $72 \mathrm{~h}$ before measuring their percentage reduction in weight. Thermogravimetric analysis (TGA) was performed with a thermal analyzer (TG209F1, Netzsch, Germany) in $\mathrm{N}_{2}$ atmosphere $(50 \mathrm{~mL} / \mathrm{min})$. The samples were heated in open alumina crucibles and scanned from $50{ }^{\circ} \mathrm{C}$ to $600^{\circ} \mathrm{C}$ at a rate of $10^{\circ} \mathrm{C} / \mathrm{min}$. Limiting oxygen index (LOI) values were determined with a HC-2C oxygen index meter (Nanjing, China) according to Chinese Standard GB/T 2406.1-2008 [14]. Scanning electron microscopy (SEM, Hitachi Model JSM7500F, Japan) was employed to investigate the surface morphologies of the char residues of PVC/CFAMEx coatings after LOI tests. The tensile strength and elongation at break of the PVC coatings were measured according to ASTM D-638 standard [15] using a universal testing machine (GT-A1-7000S, Chengdu GT Test Machine Co. Ltd., China) with a tensile rate of $100 \mathrm{~mm} / \mathrm{min}$ at room temperature. The reported data were mean of triplicate samples for each measurement.

\section{Results and discussion}

To determine the optimal condition for efficient production of CFAME, the influence of chlorinating time on chlorinity of CFAME was first evaluated by a single factor experiment. The chlorinating reaction was carried out at $80^{\circ} \mathrm{C}$, while the flow rate of chlorine was set at $50 \mathrm{~mL} / \mathrm{min}$. According to Fig. 1 (a), the chlorinity experienced a surge over the first $10 \mathrm{~h}$, and then leveled off as the chlorinating time elapsed further. For time efficiency therefore, we chose $10 \mathrm{~h}$ as the optimal reaction time to maximize chlorinity that was closely associated flame retardancy of the final CFAME. Temperature imposes influence upon both rate and extent of most chemical reactions. In our experiment, five temperatures, i.e. 20, $40,60,80,100^{\circ} \mathrm{C}$, were selected to run the CFAME preparation experiment. As illustrated in Fig. 1 (b), as $10 \mathrm{~h}$ elapsed at a chlorine flow rate of $50 \mathrm{~mL} / \mathrm{min}$, a maximal chlorinity of approximately $27 \%$ could be obtained at $80^{\circ} \mathrm{C}$ or higher. Since yellowing occurred at higher temperature, which posed adverse effect on appearance of the final plasticizer, we chose $80^{\circ} \mathrm{C}$ as the optimal reaction temperature in further experiment. Figure 1 (c) illustrated the chlorinity of the resulting 

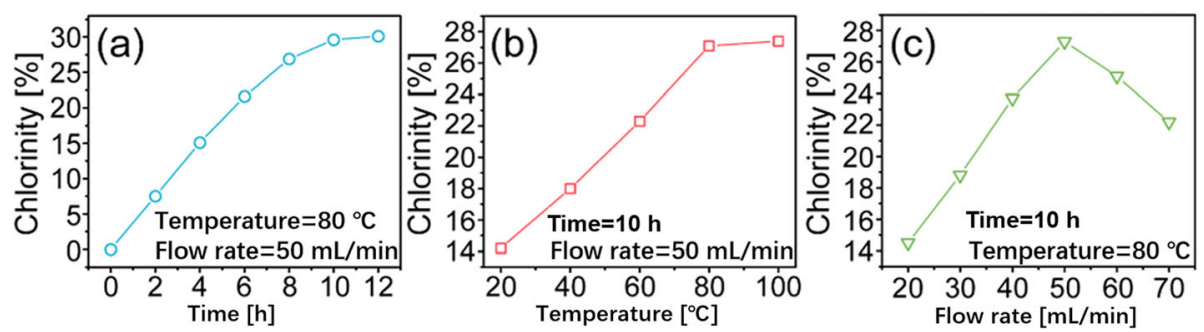

Fig. 1 Chlorinity of CFAME as a function of (a) chlorinating time, (b) reaction temperature, and (c) flow rate of chlorine

CFAME as a function of flow rate of chlorine. At a fixed reaction time $(10 \mathrm{~h})$ and temperature $\left(80^{\circ} \mathrm{C}\right)$, the chlorinity displayed a unimodal dependence upon the flow rate of chlorine, with the maximum occurring at $50 \mathrm{~mL} / \mathrm{min}$. Higher gas flow rate had a negative effect upon chlorinity, simply because insufficient contact with the feedstocks occurred in this case. From the abovementioned experimental results, we obtained the optimal condition $\left(10 \mathrm{~h} ; 80^{\circ} \mathrm{C}\right.$; flow rate of chlorine at $50 \mathrm{~mL} / \mathrm{min}$ ) to prepare CFAME with a high chlorinity (29.6\%) and, hence, flame retardant efficiency for the following characterization.

Successful chlorination, as well as reactive site, of the feedstock at the optimal condition could be confirmed by a combination of the following techniques. The FTIR spectra of FAME and CFAME were compared in Fig. 2. In comparison with FAME, the absorption (3007 $\mathrm{cm}^{-1}$ ) derived from stretching vibration of carboncarbon double bond disappeared completely in the spectrum of CFAME, accompanied by a significant decrease of iodine value from approximately $62 \mathrm{gI}_{2} / 100 \mathrm{~g}$ in FAME to $2 \mathrm{gI}_{2} / 100 \mathrm{~g}$ in CFAME. Meanwhile, as a result of chlorination, two new stretching peaks appeared at $654 \mathrm{~cm}^{-1}$ and $610 \mathrm{~cm}^{-1}$ in CFAME, both attributable to the absorption of $-\mathrm{C}-\mathrm{Cl}$. These results indicated that chlorination occurred at the carbon-carbon double bond position in FAME, affording a bio-plasticizer with two chlorine moieties existing in one molecule.

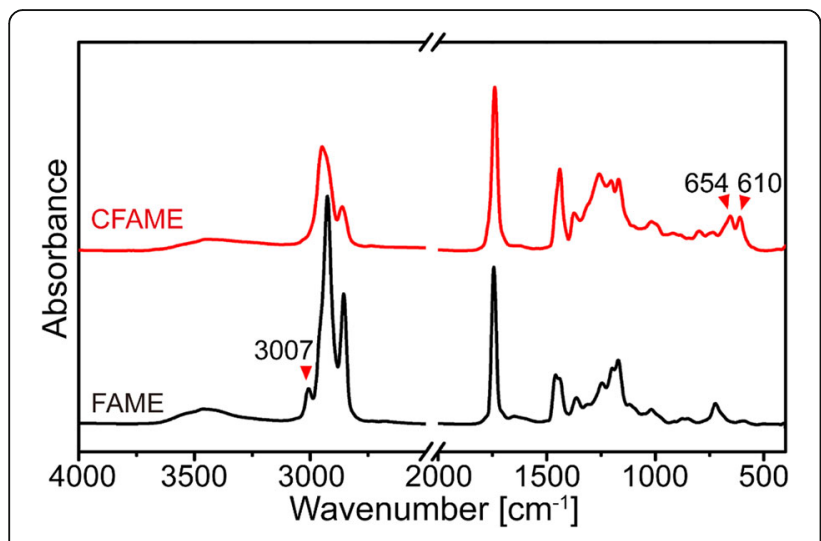

Fig. 2 FT-IR spectra of CFAME and FAME
Subsequently, GC-MS analysis was adopted to characterize the composition of CFAME. According to the GC-MS data presented in Fig. 3 and Table 2, methyl myristate, methyl hexadecanoate, methyl stearate, methyl stearate, and methyl eicosanoate were detected in CFAME. They were all saturated fatty acid methyl ester, which could not be chlorinated via direct contact with chlorine gas. In addition, a series of chromatogram peaks associated with chlorinated methyl oleate (methyl 9,10dichloro-octadecanoate) were discerned in the retention time range of $37-41 \mathrm{~min}$. These results were in good agreement with FT-IR analysis, which confirmed that chlorination occurred at the carbon-carbon double bond position in FAME. Accordingly, if higher chlorinity and, hence, flame retardancy were expected, unsaturated fatty acid methyl ester with higher iodine value should be employed as feedstock.

Following FT-IR and GC-MS analysis that provided chemical structure of CFAME, we then turned to investigate whether the engineered plasticizer could act as a co-plasticizer to partially replace DOP for PVC processing. The storage modulus and loss factor of the PVC coatings containing varying percentage of CFAME in the

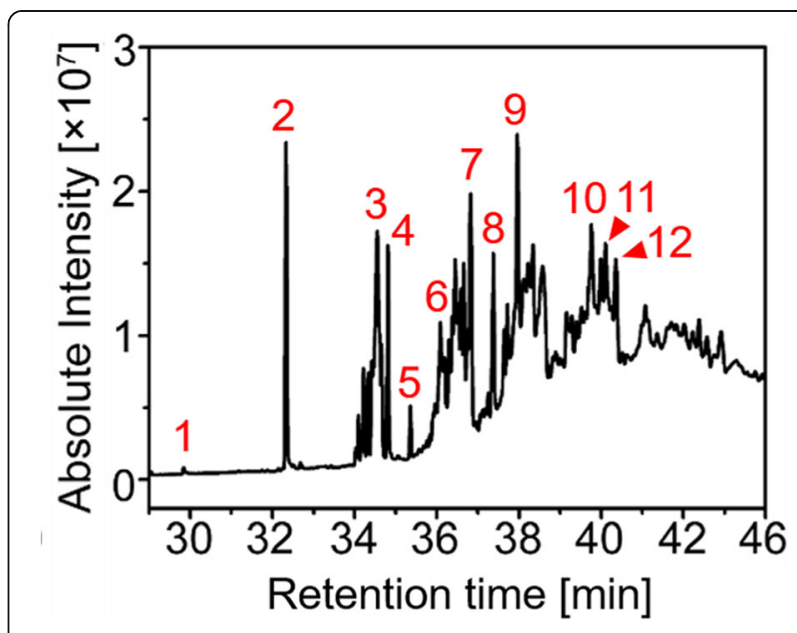

Fig. 3 Gas chromatograms of CFAME. Overlapped chromatographic peaks and baseline drift were observed, which could be attributed to mismatch between multipolarity of the chlorinated components and unipolarity of the chromatographic column 
Table 2 Composition of CFAME identified by comparing the experimental mass spectra of the components in Fig. 3 against NIST08 mass spectral library

\begin{tabular}{llll}
\hline Peak & Retention time (min) & Component & Molecular formula \\
\hline 1 & 32.3 & Methyl myristate & $\mathrm{C}_{15} \mathrm{H}_{30} \mathrm{O}_{2}$ \\
2 & 34.5 & Methyl hexadecanoate & $\mathrm{C}_{17} \mathrm{H}_{34} \mathrm{O}_{2}$ \\
3 & 34.8 & Methyl stearate & $\mathrm{C}_{19} \mathrm{H}_{38} \mathrm{O}_{2}$ \\
4 & 35.4 & Methyl stearate & $\mathrm{C}_{19} \mathrm{H}_{38} \mathrm{O}_{2}$ \\
5 & 36.1 & Methyl stearate & $\mathrm{C}_{19} \mathrm{H}_{38} \mathrm{O}_{2}$ \\
6 & 36.8 & Methyl eicosanoate & $\mathrm{C}_{21} \mathrm{H}_{42} \mathrm{O}_{2}$ \\
7 & 37.4 & Methyl 9,10-dichloro-octadecanoate & $\mathrm{C}_{19} \mathrm{H}_{36} \mathrm{Cl}_{2} \mathrm{O}_{2}$ \\
8 & 38.6 & Methyl 9,10-dichloro-octadecanoate & $\mathrm{C}_{19} \mathrm{H}_{36} \mathrm{Cl}_{2} \mathrm{O}_{2}$ \\
9 & 40.0 & Methyl 9,10-dichloro-octadecanoate & $\mathrm{C}_{19} \mathrm{H}_{36} \mathrm{Cl}_{2} \mathrm{O}_{2}$ \\
10 & 40.1 & Methyl 9,10-dichloro-octadecanoate & $\mathrm{C}_{19} \mathrm{H}_{36} \mathrm{Cl}_{2} \mathrm{O}_{2}$ \\
11 & 40.4 & Methyl 9,10-dichloro-octadecanoate & $\mathrm{C}_{19} \mathrm{H}_{36} \mathrm{Cl}_{2} \mathrm{O}_{2}$ \\
12 & 40.4 & Methyl 9,10-dichloro-octadecanoate & $\mathrm{C}_{19} \mathrm{H}_{36} \mathrm{Cl}_{2} \mathrm{O}_{2}$ \\
\hline
\end{tabular}

plasticizer mixture were determined by DMA technique, and the results were illustrated in Fig. 4. The storage modulus indicated the plasticizing effect, while the peak in the loss factor curve with increasing temperature corresponded to the glass transition temperature of the PVC coating, which was an important index for plasticizing efficiency. According to Fig. 4 (a), the storage modulus increased with increasing percentage of CFAME in the formulations. This was because one CFAME contained two polar chlorine moieties, which displayed strong polar interaction with chlorinecontaining PVC, counteracting the random motion of the PVC chains. Accordingly, the glass transition temperature of the PVC coatings experienced an increase from $4{ }^{\circ} \mathrm{C}$ to $21^{\circ} \mathrm{C}$ as the percentage of CFAME in the plasticizer mixture increased from $0 \%$ up to $100 \%$ (Table 3). For comparison, we also determined the glass transition temperature $\left(101^{\circ} \mathrm{C}\right)$ of pure PVC by DMA technique. According to the extent of reduction in glass transition temperature from that of pure PVC, the plasticizing efficiency of pure CFAME was calculated to be $82.5 \%$ relative to pure DOP. In general, a plasticizing efficiency higher than $80 \%$ was acceptable as far as a coplasticizer was concerned [4].

In addition, PVC resin and the plasticizers are thermodynamically incompatible, so the plasticizers are inclined to migrate from the PVC coating, shorting the service life of PVC artificial materials. This is particularly true for many halogen-free intrinsically flame-retardant plasticizers in that they usually display weak interaction with PVC matrix despite of flame retardancy $[3,16]$. Herein, chlorinating FAME yielded a bio-plasticizer with two chlorine moieties that displayed strong polar interaction with PVC, and thus the migration of CFAME could be significantly suppressed compared with other chlorinefree substitutes. This conclusion was demonstrated in this study by measuring the weight loss of CFAMEplasticized PVC coatings in both air and cyclohexane. As shown in Fig. 5, CFAME was as resistant as DOP in migration when the experiment was carried out in air. The migration ratio only increased slightly from $0.24 \%$ to $0.30 \%$ as the percentage of CFAME in the plasticizer mixture increased from $0 \%$ to $100 \%$. According to international standard ISO177:2016 (E) [13], a compound is
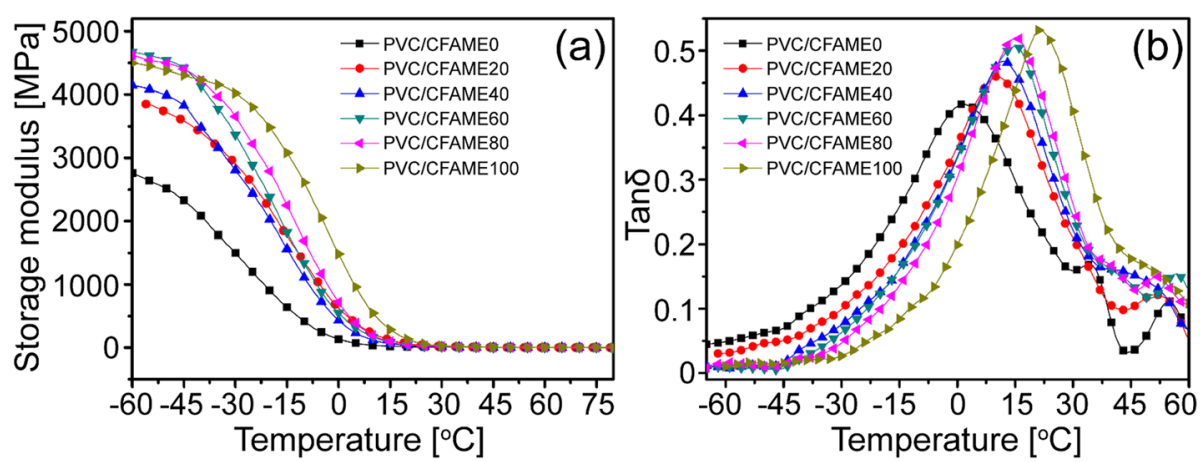

Fig. 4 a Storage modulus and $\mathbf{b}$ loss factor of PVC/CFAMEx coatings as determined by DMA technique 
Table 3 Glass transition temperatures of PVC/CFAMEx coatings as determined by DMA analysis

\begin{tabular}{ccccccc}
\hline & PVC/CFAMEO & PVC/CFAME20 & PVC/CFAME40 & PVC/CFAME60 & PVC/CFAME80 & PVC/CFAME100 \\
\hline $\mathrm{T}_{\mathrm{g}}\left({ }^{\circ} \mathrm{C}\right)$ & 4 & 10 & 12 & 15 & 15 & 21 \\
\hline
\end{tabular}

qualified as a PVC plasticizer as long as the weight loss percentage of the plasticized PVC coating does not exceed $0.5 \%$. Subsequently, we immersed the PVC coating into cyclohexane, a non-polar solvent, to test whether CFAME was vulnerable to extraction. In cyclohexane, pure CFAME seldom migrated, exhibiting significantly improved migration resistance than DOP, which was found to have a migration ratio of $13.2 \%$ at the end of the experiment. These results indicated that the polar chlorine moieties in CFAME formed strong interaction with PVC chains, which enabled long-lasting service life of PVC artificial materials.

In the manufacturing process of PVC artificial materials, the temperature in the plasticizing oven is typically set in the range of $130-170{ }^{\circ} \mathrm{C}$. Accordingly, the plasticizers are anticipated to exhibit excellent thermal stability, or they may be subject to decomposition over the plasticizing procedure. Here, we employed TGA technique to analyze the thermal stability of CFAME; the TGA curves and their first derivatives (DTA) were illustrated in Fig. 6 (a) and (b), respectively, for comparison. According to the TGA curves (Fig. 6 (a)), $\mathrm{T}_{\mathrm{d} 5}$ (the temperature where $5 \mathrm{wt} \%$ weight loss of the PVC coating occurred), $\mathrm{T}_{\max }$ (the temperature where the maximum decomposition took place), and $Y_{c}$ (the char residues at $600{ }^{\circ} \mathrm{C}$ ) were calculated and tabulated in Table 4. It was found that PVC coatings with varying percentage of CFAME as a co-plasticizer were thermally stable in $\mathrm{N}_{2}$ atmosphere below $200^{\circ} \mathrm{C}$. Once heated above $200^{\circ} \mathrm{C}$, the TGA curves illustrated a typical two-stage

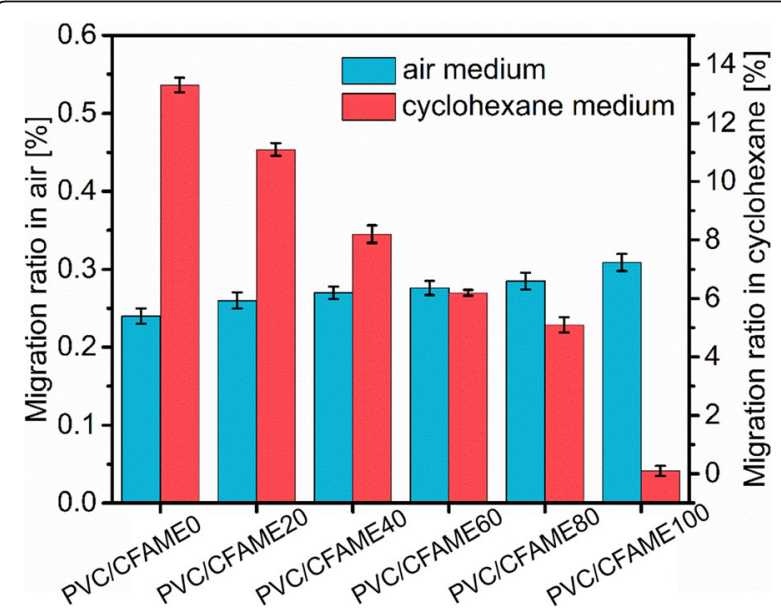

Fig. 5 Migration ratio of PVC/CFAMEX coatings in air at $70^{\circ} \mathrm{C}$ for 48 $\mathrm{h}$ and in cyclohexane medium at $30^{\circ} \mathrm{C}$ for $48 \mathrm{~h}$ degradation process. The first degradation stage took place in the temperature range of $220-400{ }^{\circ} \mathrm{C}$, which might be ascribed to dehydrochlorination of PVC and thermal degradation of small molecular plasticizer [1719]. The second stage occurred between 400 and $500{ }^{\circ} \mathrm{C}$, mainly involving further cross-linking of olefin and polyolefin generated by degradation of PVC, and the product derived from cyclic olefin and aromatic compounds cyclization $[20,21]$. This two-stage degradation process could also be observed in the DTA curves (Fig. 6 (b)). From the data in Table 4, as the percentage of CFAME increased from 0 to $100 \%$ in the plasticizer mixture, $\mathrm{T}_{\mathrm{d} 5}$ and $\mathrm{T}_{\max }$ of the PVC coatings increased gradually with the char residues yield at $600{ }^{\circ} \mathrm{C}$ increasing from $6.0 \%$ to $8.4 \%$. This phenomenon indicated that the presence of CFAME could improve the thermal stability of the PVC coating, and furthermore contributed to formation of char yield. The high char yield would decelerate the transfer of heat, oxygen and combustible gas in the combustion process, so as to improve the flame-retardant performance of PVC artificial materials.

The limiting oxygen index test is probably the most widely employed method for assessing flammability. In this test, the minimum oxygen fraction in an oxygen/nitrogen mixture that supports combustion of a candlelike sample under specified test conditions is measured. The top edge of the test sample is ignited, and the oxygen concentration in the flow is decreased until the flame is no longer supported. Generally, materials with LOI less than $21 \%$ are classified as combustible, but those with LOI far greater than 21 are classed as selfextinguishing since their combustion cannot be sustained [22]. This method remains one of the most important screening and quality control tools in the plastics industry to characterize both the ignitability and flammability resistance. To investigate the flameretardant properties that CFAME could endow the PVC coating with, the LOIs of the PVC/CFAME $x$ coatings were measured according to Chinese Standard GB/T 2406.1-2008 [14]. According to the data in Fig. 7, the PVC coating plasticized by DOP alone exhibited a low LOI of $21.5 \%$, in agreement with previous conclusion that ordinary plasticizer such as DOP was responsible for flammability of otherwise nonflammable PVC coating. As the proportion of CFAME increased up to $100 \%$ in the plasticizer mixture, the LOI of the PVC coating increased to $27.1 \%$, showing self-extinguishing behavior, similar to that of flexible PVC prepared from other intrinsically flame-retardant plasticizer previously reported 

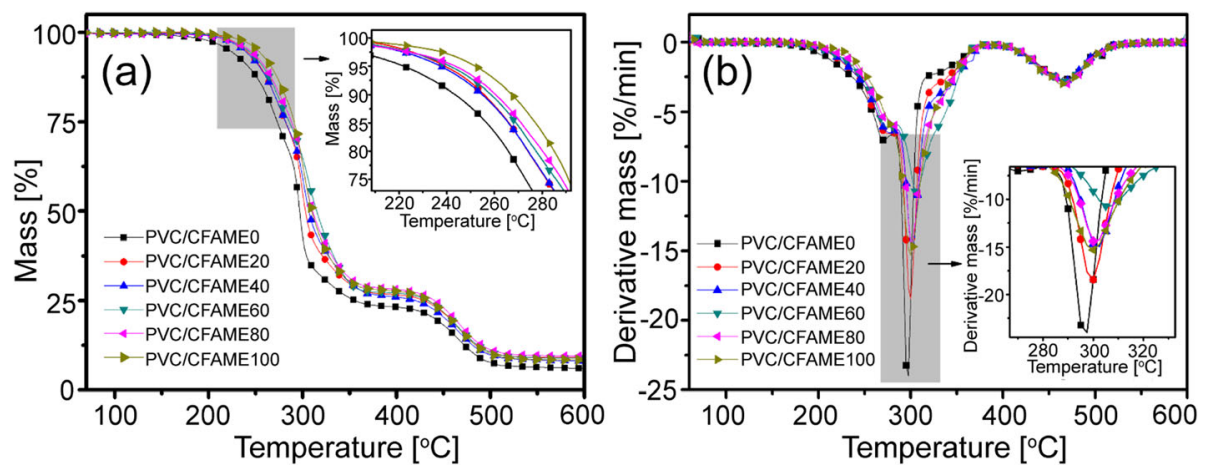

Fig. $\mathbf{6}$ a TGA and $\mathbf{b}$ DTG curves of PVC/CFAMEx coatings

[9]. This result confirmed that chlorinating unsaturated fatty acid methyl ester yielded an intrinsically flameretardant bio-plasticizer that could endow the PVC coating with excellent flame retardance.

To further explore the flame-retardant mechanism of CFAME, the surface morphology of char residues derived from LOI experiment was analyzed by SEM, and the results were demonstrated in Fig. 8. It could be seen in Fig. 8 (a) that the char residues of PVC coating plasticized with DOP alone were fragmented. Therefore, it could not efficiently shield the underlying PVC from flame and heat. As the percentage of CFAME in the plasticizer mixture increased, a more compact and continuous charring layer was detected, resembling a "carbonaceous clothes" dressed on the polymer. This charring layer imparted PVC with flame retardancy because it delayed thermal degradation of PVC materials, prevented volatilization of thermal degradation products, and shielded the underlying PVC from further attacking of heat flux. Based on these results, it could be concluded that the engineered CFAME herein was an efficient carbonization agent to enhance the formation of thermally stable char, which was advantageous to obstruct the exothermicity of pyrolysis reaction, block the volatilizable gases, and impede the thermal conductivity of substance, thus endowing PVC materials with flame retardancy.

Inorganic flame retardants are incompatible with PVC, which are known to deteriorate the mechanical property of the PVC coating. Since the choline moieties were

Table 4 TGA data of PVC/CFAMEx coatings

\begin{tabular}{llll}
\hline & $\mathrm{T}_{\mathrm{d} 5}\left({ }^{\circ} \mathrm{C}\right)$ & $\mathrm{T}_{\max }\left({ }^{\circ} \mathrm{C}\right)$ & $\mathrm{Y}_{\mathrm{c}}$ at $600{ }^{\circ} \mathrm{C}(\%)$ \\
\hline PVC/CFAME0 & 221.9 & 296.6 & 6.0 \\
PVC/CFAME20 & 239.2 & 299.4 & 9.0 \\
PVC/CFAME40 & 237.3 & 301.6 & 8.1 \\
PVC/CFAME60 & 241.2 & 305.9 & 9.1 \\
PVC/CFAME80 & 243.5 & 301.1 & 9.4 \\
PVC/CFAME100 & 252.0 & 300.2 & 8.4 \\
\hline
\end{tabular}

covalently attached to the plasticizer, the engineered products should be totally compatible with PVC, which would not compromise the mechanical properties of the PVC coating. This conclusion was verified herein by measuring the tensile strength and elongation at break of the PVC coatings. According to the results in Fig. 9, as the percentage of CFAME increased from 0 to $100 \%$ in the plasticizer mixture, the tensile strength of the PVC coating increased from 9.5 to $13.9 \mathrm{MPa}$, while the elongation at break experienced a slight decrease from $237 \%$ to $193.7 \%$, indicating that CFAME would not lead to a remarkable decline of the mechanical properties of the PVC coatings as the inorganic flame retardants $[6,7]$.

\section{Conclusion}

In conclusion, we have proposed a simple strategy to prepare intrinsically flame-retardant plasticizer from renewable bio-resources, unsaturated fatty acid methyl ester, and cheap chlorine gas. When combined with DOP, CFAME was qualified as a co-plasticizer, which displayed acceptable plasticizing effect, plasticizing efficiency, migration, and thermal stability. Upon

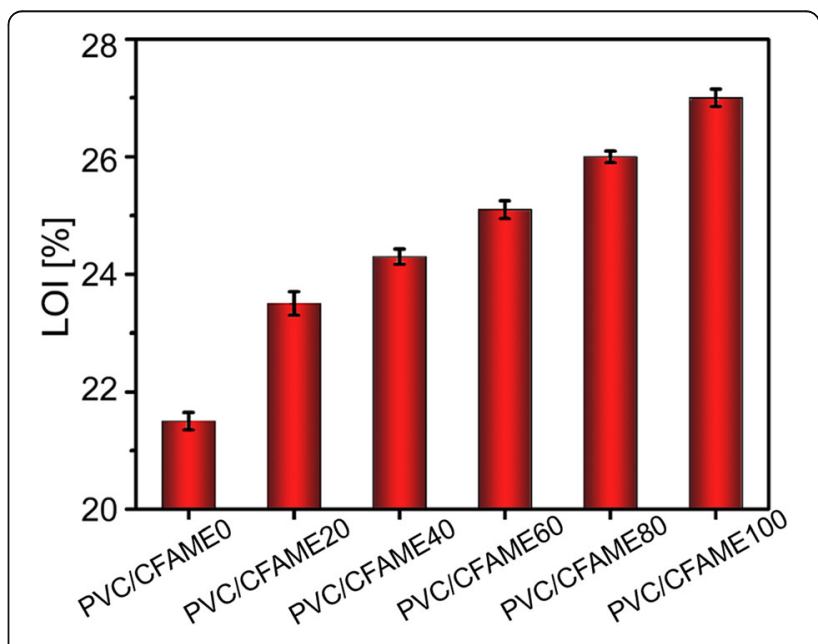

Fig. 7 LOI of PVC/CFAMEX coatings 

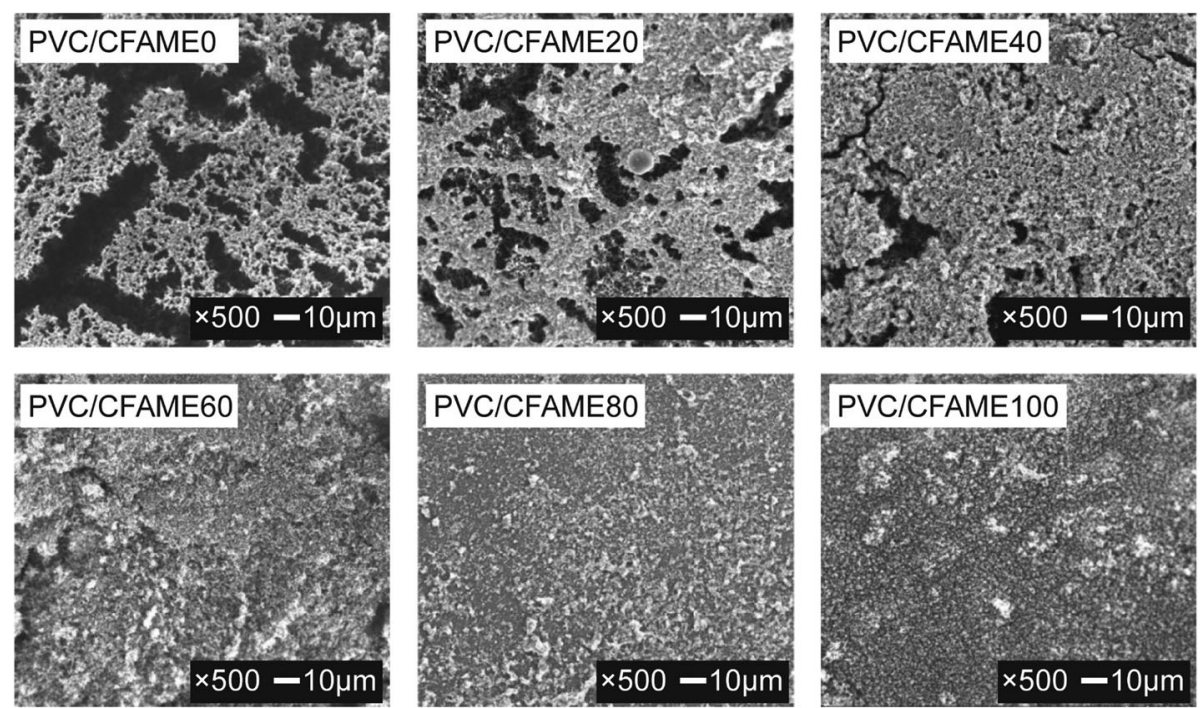

Fig. 8 SEM images concerning the surface morphology of char residues obtained from LOI experiment

igniting, the chlorine moieties promoted formation of a dense and compact char, therefore reducing the amount of flammable volatiles released into the fire, endowing the PVC coating with flame retardancy. Since CFAME was totally compatible with PVC, the mechanical properties of the PVC coating did not deteriorate as in the case of inorganic flame retardants. Compared with previous reported intrinsically flameretardant plasticizer that invariably required either expensive starting materials or laborious and tedious procedures, the production of CFAME was simple and cost efficient, displaying scale-up potential to enable flame-retardant PVC artificial materials.

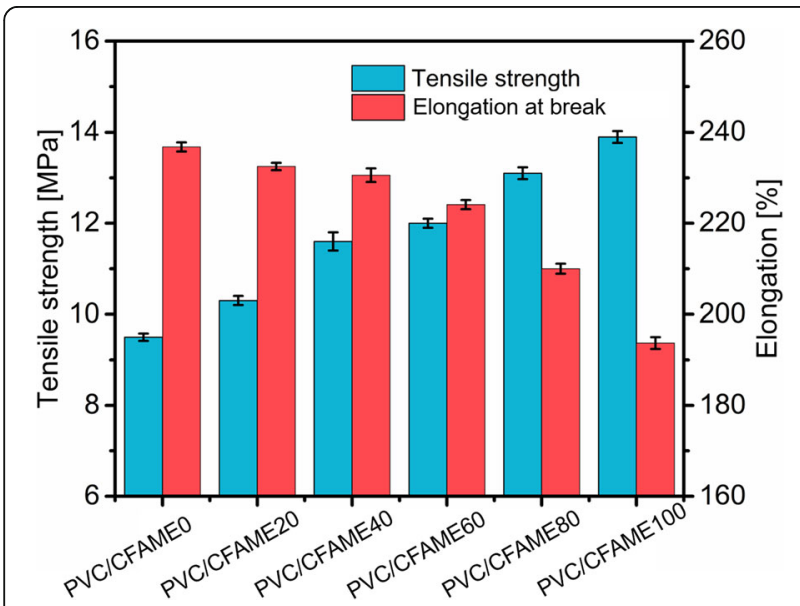

Fig. 9 Tensile strength and elongation at break of the PVC/CFAMEX coatings
Acknowledgements

Not applicable.

\section{Authors' contributions}

Yong Xu synthesized the CFAME plasticizer, measured the LOI of the PVC membranes, and interpreted all data. He was also a major contributor in writing the manuscript. Songhang Wang performed the FT-IR and SEM experiment. Jinming Chang and Zhou Xu performed the GC-MS experiment. Q Zeng and Zhonghui Wang determined the chlorinity and iodine value of the plasticizer, and carried out the TGA and DMA analysis. Jun Yan proposed the technique route to synthesize the CFAME plasticizer. Yi Chen evaluated plasticizer migration from the PVC membranes and measured the mechanical properties of the PVC membranes. The authors read and approved the final manuscript.

\section{Funding}

We gratefully acknowledge financial support of this work by National Key Research and Development Program of China (2017YFB0308600), Science and Technology Planning Project of Sichuan Province (20YYJC3727), National Natural Science Foundation of China (21878196), and Fundamental Research Funds for the Central Universities, China (20826041C4159).

\section{Availability of data and materials}

All data generated or analysed during this study are included in this published article.

Competing interests

The authors declare that they have no competing interests.

\section{Author details}

${ }^{1}$ College of Biomass Science and Engineering, Sichuan University, Chengdu 610065, P.R. China. ${ }^{2}$ Key Laboratory of Leather Chemistry and Engineering of Ministry of Education, Sichuan University, Chengdu 610065, P.R. China. ${ }^{3}$ Chemical Synthesis and Pollution Control Key Laboratory of Sichuan Province, China West Normal University, Nanchong 637009, P.R. China. ${ }^{4}$ Chemical Synthesis and Pollution Control Key Laboratory of Sichuan Province, College of Chemistry and Chemical Engineering, China West Normal University, Nanchong 637000, P.R. China. ${ }^{5}$ School of Life Science and Food Engineering, Yibin University, Yibin 644007, P.R. China. 
Received: 14 February 2020 Accepted: 30 March 2020

Published online: 15 April 2020

\section{References}

1. Wang FC-Y. Polymer additive analysis by pyrolysis-gas chromatography: II. Flame retardants. J Chromatogr A. 2000;886:225-35.

2. Lenoir D, Kampke-thiel K. Formation of polybrominated dibenzodioxins and dibenzofurans in laboratory combustion processes of brominated flame retardants. In: Nelson GL, editor. Fire and polymers II. American Chemical Society; 1995. p. 377-92.

3. Jia P, Zhang M, Liu C, Hua L, Feng G, Bo C, et al. Effect of chlorinated phosphate ester based on castor oil on thermal degradation of poly (vinyl chloride) blends and its flame retardant mechanism as secondary plasticizer. RSC Adv. 2015;5:41169-78.

4. Pan S, Hou D, Yang G, Xie Q, Yan S, Zeng Q, et al. Epoxidized methyl ricinoleate bio-plasticizer with a pendant acetate ester for PVC artificial material: circumventing existing limit on achievable migration resistance. J Leather Sci Eng. 2019;1:2

5. Azeddine R, Djarmal Z, Michel A, Abdellah H. Spectroscopic and mechanical properties of PVC plasticized by bio-plasticizer ESO. J Polymer Res. 2020;27:1.

6. $L u ~ H$, Song $L, H u$ Y. A review on flame retardant technology in China part II: flame retardant polymeric nanocomposites and coatings. Polymers Adv Technol. 2011;22:379-94.

7. Hongqiang $Q$, Wu W, Zheng $Y$, Xie J, Jianzhong X. Synergistic effects of inorganic tin compounds and $\mathrm{Sb}_{2} \mathrm{O}_{3}$ on thermal properties and flame retardancy of flexible poly(vinyl chloride). Fire Saf J. 2011:46:462-7.

8. Jia P, Hu L, Feng G, Bo C, Zhou J, Zhang M, et al. Design and synthesis of a castor oil based plasticizer containing THEIC and diethyl phosphate groups for the preparation of flame-retardant PVC materials. RSC Adv. 2017;7:897903.

9. Wang F, Pan S, Zhang P, Fan H, Chen Y, Yan J. Synthesis and application of phosphorus-containing flame retardant plasticizer for polyvinyl chloride. Fibers and Polymers. 2018;19:1057-63.

10. Chaudhary BI, Nguyen B-D, Zamanskiy A. Dialkyl furan-2,5-dicarboxylates, epoxidized fatty acid esters and their mixtures as bio-based plasticizers for poly(Vinylchloride). J Appl Polym Sci. 2015;132:32.

11. Chlorinated paraffines-Determination of chlorine content-Mercurimetric method. Chinese Chemical Industry HG standardization, HG 3017-1988 (English version). 1988.

12. Determinating the iodine value of plasticizers. Chinese National GB standardization, GB/T 1676-2008 (English version). 2008.

13. Plastics-Determination of Migration of Plasticizers. International Standard ISO 177:2016(E).

14. Plastics-Determination of burning behaviour by oxygen index. National GB standardization, GB/T 2406.1-2008. 2008.

15. Standard test method for tensile properties of plastics. American Society for Testing Materials, ASTM D-638. 2015.

16. Pan S, Hou D, Chang J, Xu Z, Wang S, Yan S, et al. A potentially general approach to aliphatic ester-derived PVC plasticizers with suppressed migration as sustainable alternatives to DEHP. Green Chem. 2019;21:643040.

17. Pospišil J, Horák Z, Kruliš Z, Nešpůrek S, Kuroda S-i. Degradation and aging of polymer blends I. thermomechanical and thermal degradation. Polym Degrad Stab. 1999;65:405-14

18. Yu J, Sun L, Ma C, Yu Q, Yao H. Thermal degradation of PVC: a review. Waste Manag. 2016;48:300-14.

19. Zhu H, Jiang $X$, Changming D, Chi Y, Cen K. TG-FTIR analysis of PVC thermal degradation and $\mathrm{HCl}$ removal. J Anal Appl Pyrolysis. 2008;82:1-9.

20. Pampadykandathil L, Thomas S. Thermal behaviour of polymer blends: a comparison of the thermal properties of miscible and immiscible systems. Polym Degrad Stab. 1993;41:59-64.

21. McNeill IC, Memetea $L$, Cole WJ. A study of the products of PVC thermal degradation. Polym Degrad Stab. 1995;49:181-91.

22. Xu Y, Wang J, Tan Y, Qi M, Chen L, Wang Y. A novel and feasible approach for one-pack flame-retardant epoxy resin with long pot life and fast curing. Chem Eng J. 2018:337:30-9.

\section{Publisher's Note}

Springer Nature remains neutral with regard to jurisdictional claims in published maps and institutional affiliations.

\section{Submit your manuscript to a SpringerOpen ${ }^{\circ}$ journal and benefit from:}

- Convenient online submission

- Rigorous peer review

- Open access: articles freely available online

High visibility within the field

- Retaining the copyright to your article

Submit your next manuscript at $\boldsymbol{\nabla}$ springeropen.com 